\title{
短纎維強化複合材料の破壊過程の超音波顕微鏡解析
}

$$
\begin{aligned}
& \text { 東京大学先端科学技街研究センター 武田 展雄 } \\
& \text { 日 本硝子維 中田数夫 } \\
& \text { オリンパス光学工業懒宮坂千晶 }
\end{aligned}
$$

\section{Fracture Process Analysis of Short Fiber Composites by Scanning Acoustic Microscopy}

\author{
Nobuo Takeda ${ }^{* 1}$, Kazuo Nakata*2, and Chiaki Miyasaka*3 \\ * 1 Research Center for Advanced Science and Technology, The University of Tokyo \\ 4-6-1 Komaba, Meguro-ku, Tokyo, 153 Japan \\ *2 Nippon Glass Fiber Co., Ltd., Takajaya, Tsu-City, Mie Pref., 514.91 Japan \\ *3 Olympus Optical Co., Ltd., 1.22-2 Nishi-Shinjuku, Shinjuku-ku, Tokyo, 163-91 Japan
}

\begin{abstract}
Three different fiber surface treatments were made to study their influences on drop-weight impact fracture resistance and static in-plane fracture toughness of injection-molded short glass fiber. reinforced nylon 6 plates. Scanning acoustic microscopy (SAM) was used to study the microscopic deformation and fracture processes in detail. The SAM observation revealed several fundamental and quantitative features such as: (1) three-dimensional shape of the crack front, (2) three-dimensional distribution of fibers, (3) matrix plastic deformation and/or matrix microcracking, and (4) fiber/matrix debonding and pull-out. These microscopic deformation and fracture features revealed some of the toughning mechanisms, which were then correlated with the macroscopic static and impact fracture properties. The excellent ultrasonic contrast between fiber and matrix could be accomplished by a large difference in acoustic impedance. The plastic deformation of matrix was detected by enhanced attenuation of surface waves. Moreover, fiber $/ \mathrm{ma}$. trix debonding and/or matrix microcracking were clearly observed due to the waves reflected at debonded or cracked interfaces.
\end{abstract}

(Received July 28, 1992)

\section{1. 腥官}

射出成形品であるランダム配向ガラス短轿維強化熟可 塑性樹脂複合材料(GFRTP) 仗，航空宇宙，自動車，ス ポーツ分野をはしめとする広い分野における構造用材料 として注目されている。このため，静的な強度や破堙靸

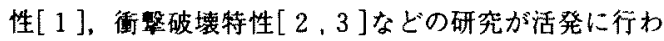
れている。筆者ら[4]は，静的，德撃雨焦荷条件におい ての GFRTP の変形・破壊特性が, 絏維表面処理条件に 强く依存することを明らかにした。しかし，製造条件と 直接結びつく娬維，樹脂及び誡維/樹脂界面などの構成 要素が微梘的破壊プロセスに与える基本的役割を理解す るまでには到らなかった。この目的のためには，超音波
顕微鏡(Scanning Acoustic Microscope, SAM)が有望であ ることが指摘されている[5，6]。一般に，複合材料を 情成する各材料は超音波伝播特性が異なることから，構 成材料間の界面の変形・破唗特性が中心となる微視的な 破壊プロセス、メカニズム(マイクロフラクチャメカニ クス)の実験的な理解には、 SAM が有力な観祭・評価手 段となる。

本研究の目的は，ナイロン6をマトリックスとする射 出成形 GFRTP の，引張負荷下き裂先端近傍における微 視的な变形・損稘・破壊プロセスを，SAM 微視観察に より明らかにすることにある。とくに，3種類の異なる 織維表面処理が変形・損甥・破壊プロ七スに与える効果 を明らかにすることにより，高鞉化メカニスムの相遧を 
明らかにする。またこれら微視的力学特性を巨視的な 力学特性である静的面内破壊靭性や落鍾衝整破壊特性と 関連づける。

\section{2. 実験}

\section{1 実段材料と力学特性}

実験に用いたガラス短䇅維ランダム方向強化ナイロン 6 射出成形板(繊維重量含有率 $30 \%, 60 \mathrm{~mm} \times 60 \mathrm{~mm} \times$ $3 \mathrm{~mm}$ )は, 表 1 に示す 3 種の異なるサイズ刻(以下，A， B，Cと示す)で表面処理したガラス短織維(平均織維直

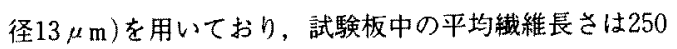
$\mu \mathrm{m}$ である。サイズ剂 C は集束用接着剤，シランカッ プリング剂，潤滑用助冎すべてを含むのに対し、サイズ

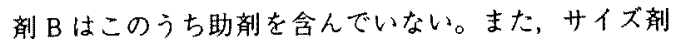
A は助剂，カップリング剂耐者を含まない。界面強度は A，B，Cの順に増加すると考えられる。射出成形板中の 短縺維はほぼ面内に配向しているが，完全な 2 次元ラン ダム配向ではなく，表面層では主として備維は射出方向
(L)に向いているのに対し，内部のコア層ではむしろ射 出方向に垂直な方向 $(T) に$ 向いている。また, 各材料の 強度比較では $\mathrm{A}<\mathrm{B} \leqq \mathrm{C}$ の順である $[4]$ 。

衝慗試験は 2 通りの方法で行った。第 1 は, 簡便なデ メポン式落下衝整試験機を用いるもので, 半径12.7 m の半球部を先端にもつ丸棒とそれに合う半径 $12.7 \mathrm{~mm}$ の 半球状凹みをるつ受台との間に試噃板を置き， $300 \mathrm{~g} の$ 重錘を一定の高さから丸棒上部に落下させ，試験板の引 張り側表面に亀裂が生じる限界落下岁さまたは衝整エネ ルギを求めた。テスト方法はJIS K7211に準拠し，50\% 破壇衝撃エネルギ $\mathrm{E}_{50}$ を求めた。第 2 は，計装化落鍾衝 慗試験機を用いるもので, 半径 $25.4 \mathrm{~mm}$ の円穴をもつ铜 製台上に置かれた試験板に，半径 $12.7 \mathrm{~mm} の$ 半球状先端 部をもつ計装化されたタップを取付けだ落錘を衝突させ る。試験板貫通に要するエネルギの䄪10倍の衝撃エネル $\neq ゙ 67 \mathrm{~J}($ 約 $11.7 \mathrm{~kg}, 3.4 \mathrm{~m} / \mathrm{s}$ )を与之, 動的荷重(吸収工ネ ルギ)一時間線図を得た。衝撃試験結果を表 2 に示す。 デェポン式落下衝慗試験から得られた $\mathrm{E}_{50}$ 値は, $\mathrm{A}<\mathrm{B}$

Table 1 Tested Materials and Their Mechanical Properties

\begin{tabular}{|c|c|c|c|c|c|}
\hline $\begin{array}{l}\text { Surface } \\
\text { treat- } \\
\text { ment }\end{array}$ & $\begin{array}{c}\text { Tensile } \\
\text { strength }^{\mathrm{a}} \text { ) } \\
(\mathrm{MPa})\end{array}$ & $\begin{array}{l}\text { EIzOD }^{\mathrm{b})} \\
\text { notched } \\
\left(\mathrm{kJ} / \mathrm{m}^{2}\right)\end{array}$ & $\begin{array}{c}\text { ElzOD }^{\mathrm{b})} \\
\text { unnotched } \\
\left(\mathrm{kJ} / \mathrm{m}^{2}\right)\end{array}$ & $\begin{array}{c}\left.\sigma_{\mathrm{B}}{ }^{\mathrm{c}}\right) \\
\mathrm{L} / \mathrm{h}=4 \\
(\mathrm{MPa})\end{array}$ & $\begin{array}{c}\left.\sigma_{B}{ }^{c}\right) \\
L / h=8 \\
(\mathrm{MPa})\end{array}$ \\
\hline A & $113.8(\mathrm{~L})$ & 5.5 & 49.5 & $\begin{array}{l}132(\mathrm{~L}) \\
142(\mathrm{~T})\end{array}$ & $\begin{array}{l}113(\mathrm{~L}) \\
100(\mathrm{~T})\end{array}$ \\
\hline B & $163.3(\mathrm{~L})$ & 8.4 & 74.3 & $\begin{array}{l}224(\mathrm{~L}) \\
187(\mathrm{~T})\end{array}$ & $\begin{array}{l}191(\mathrm{~L}) \\
149(\mathrm{~T})\end{array}$ \\
\hline C & $162.6(\mathrm{~L})$ & 8.9 & 81.8 & $\begin{array}{l}222(\mathrm{~L}) \\
209(\mathrm{~T})\end{array}$ & $\begin{array}{l}193(\mathrm{~L}) \\
153(\mathrm{~T})\end{array}$ \\
\hline
\end{tabular}

\footnotetext{
a) ASTM D638.68,

b) Izod impact value, ASTM D256-56.

c) 3.point bending strength (L: span, $h$ : thickness).

(L): Parallel to mold fill direction.

(T): Normal to mold fill direction.
}

Table 2 Summary of Impact Test Results

\begin{tabular}{cllcll}
\hline Mat'1 & \multicolumn{1}{c}{$\mathrm{E}_{50}(\mathrm{~J})$} & \multicolumn{1}{c}{$\mathrm{P}_{1}(\mathrm{kN})$} & \multicolumn{1}{c}{$\mathrm{E}_{1}(\mathrm{~J})$} & \multicolumn{1}{c}{$\mathrm{P}_{2}(\mathrm{kN})$} & \multicolumn{1}{c}{$\mathrm{E}_{\mathrm{t}}(\mathrm{J})$} \\
\hline $\mathrm{A}$ & $\left.0.65[0.69]^{\mathrm{a}}\right)$ & $1.29[0.56]$ & $0.62[0.27]$ & $1.66[0.91]$ & $5.57[0.68]$ \\
$\mathrm{B}$ & $0.82[0.87]$ & $2.10[0.91]$ & $1.85[0.80]$ & $1.95[1.07]$ & $7.49[0.92]$ \\
$\mathrm{C}$ & 0.94 & 2.29 & 2.31 & 1.82 & 8.14 \\
\hline
\end{tabular}

$E_{50}:$ Fracture energy when $50 \%$ of specimens are cracked.

$P_{1}$ : First peak load.

$E_{1}$ : Absorbed energy at $P_{1}$.

$\mathrm{P}_{2}$ : Second peak load.

$E_{q}$ : Total absorbed energy.

a) Number in $\mid$ is the ratio of each value to that of material $C$. 
くCの順である。一方，計装化落鍾衝拲試験より得ら れた第1 ピーク荷重值 $\mathrm{P}_{1}$ [吸収エネルギ $\mathrm{E}_{1}$ ] $\mathrm{A}<\mathrm{B}<$ Cの順である。この第 1 ピーク荷重が生じる原因は，上 述の $\mathrm{E}_{50}$ 値同様，引張り例の表面亀裂発生に伴うもの であることが高速度写真により確かめられている。ここ で, A，B，Cの $\mathrm{E}_{1}$ の比が $\mathrm{E}_{50}$ の比と翼なるのは，主とし て両試験において与えた衝慗エネルギの違いに伴う破壊 プロセスの相違による。

上記衝毒負荷時の亀裂発生, 進展特性に対応すべく， 静的面内亀裂発生, 進展特性を, コンパクトテンション 試駼片を用いて調べた。龟裂進展方向は射出方向と一致 させた。どン荷重 Pと、クリップゲージにより計測さ れる荷重線変位 $\delta$ とを記録するともに，変形，破壊過程 中のアコースティックエミッション(AE)信号をモ二 ターした。実験方法の詳細は文献[4]を参照されたい。 $P ー \delta$ 線图はかなりの非線形性をもつため，」積分概念 の導入が必要である。安定刍裂成長限界時の丁值(以下 $\mathrm{J}_{\mathrm{c}}$ と示す)を表 3 に示す。ここではJ ギ急增点 $\left(\delta_{\mathrm{c}}\right)$ に扔けるJ值で定義する。この $\delta_{\mathrm{c}}$ は，莗 裂先端部の観察による安定㲛裂成長限界時とほほ一致す る。各材料の $\mathrm{J}_{\mathrm{r}}$ 值の傾向は，上述の $\mathrm{E}_{50}$ の傾向とよく 一致している。この結果はFRTPに共通に言えることと 筆者は考元る。

\subsection{SAM による表面，表面下锶察}

图1に示すように，SAM(オリンパスUH-3)により。 表面または表面下 $(z<0)$ にお忛る $\mathrm{x}-\mathrm{y}$ 平面内にスキャ ンされた超音波映像を得た。まず，r.f.パルス入力を圧 電トランスデューサに供給することにより，サフフイア ロッドに維波平面波を発生させる。蒝留水を媒体として 使用し，サファイア/水界面が音響レンズを構成する。 維波は表面上または表面下の 1 点に集束される。反射波 は逆の経路を戻り，增幅後信号処理され，1点の反射波 強度が記録される。以上の測定を $\mathrm{x}-\mathrm{y}$ 平面内にスキャン することにより反射波強度分布が映像化される。本研究 では200または $400 \mathrm{MHz}$ 音翌レンズを用いた。

\section{3. 桔果と考察}

SAMによる観察例を図2〜4に示す。一般に超音波 映像のコントラストの成因は，次の 4 項目に分類され る。

(1)試料中の反射率の差によるコントラスト

(2)試料形状から生じる透過散乱によるコントラスト

(3)試料中の表面波速度の差によるコントラスト

(4)試料中の吸収の差によるコントラスト

観察したFRTP 試験片の表面状態は良好で、形状凹凸 が原因で生じる透過散乱によるコントラストは無視でき
Table $3 J_{c}$ Values

\begin{tabular}{ccl}
\hline Material & $\delta_{c}(\mathrm{~mm})$ & $J_{c}\left(\mathrm{~kJ} / \mathrm{m}^{2}\right)$ \\
\hline A & 1.37 & $\left.6.0[0.83]^{\mathrm{a}}\right)$ \\
B & 1.34 & $7.3[0.91]$ \\
C & 1.34 & 8.0 \\
\hline
\end{tabular}

a) Number in | | is the ratio of each value to that of material C

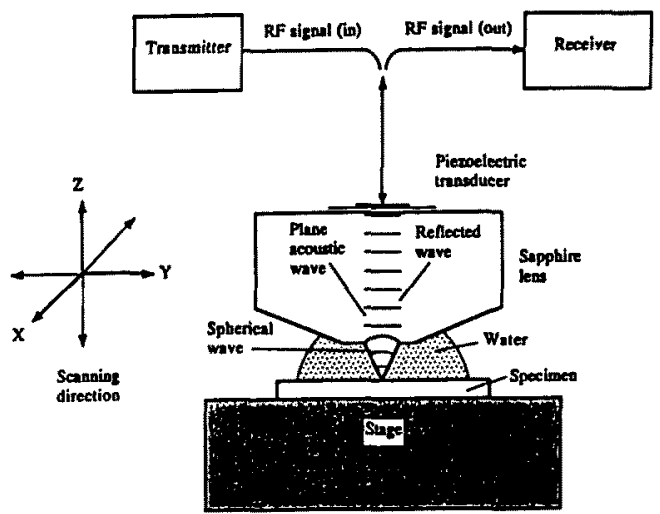

Fig. 1 Schematic drawing of scanning acoustic micro. scope observation.

る。したがって(1)，(3)，(4)について順次考察する。

(1)試料中の反射率の差によるコントラストは，音響イ ンピーダンスの差によるコントラストに置き換えて考え られる。反射率 Rは一般に次式で表される。

$\mathrm{R}=\left\{\left(Z_{1}-Z_{2}\right) /\left(Z_{1}+Z_{2}\right)\right\}^{2}$ ここで $Z_{1}, Z_{2}$ は音響インピーダンスを示す。FRTPに分 散している䄉維と樹脂相のコントラストは轿維，樹脂そ れぞれの音響インピーダンス $Z_{1}, Z_{2}$ の差，すなわち， 上記(1)が原因で生じている。このため，SAMで得られ る䄉維と樹脂相の境界は, 光学顕微鏡のそれに比へてか なり明瞭に識別できる。また，走査型電子顕微鏡ではフ ラットな面は観察しにくいが，SAMでは可能である。 さらに，㦵維／樹脂間のディボンディングに伴うコント ラストもこれが原因である。ディボンディンク領域は輝 度がきわめて高くなる(図2 )ことから知ら机る。

きて，図 3 に示した刍裂先端部の超音波映像について 考えよう。まず焦点染度 $\mathrm{z}=0 \mu \mathrm{m}$ ，すなわち表面焦点の 場合は，䄉維、樹脂間のコントラストが明確である。つ ぎに， $z=-20 \mu \mathrm{m}$ と音響レンズを試料に近づけると，表 面では観察できなかった白いコントラストの領域が観察 される。さらに $\mathrm{z}=-25 \mu \mathrm{m}$ と近づけると，その領域は消 失してくる。上記方法で観祭された的いコントラストの 


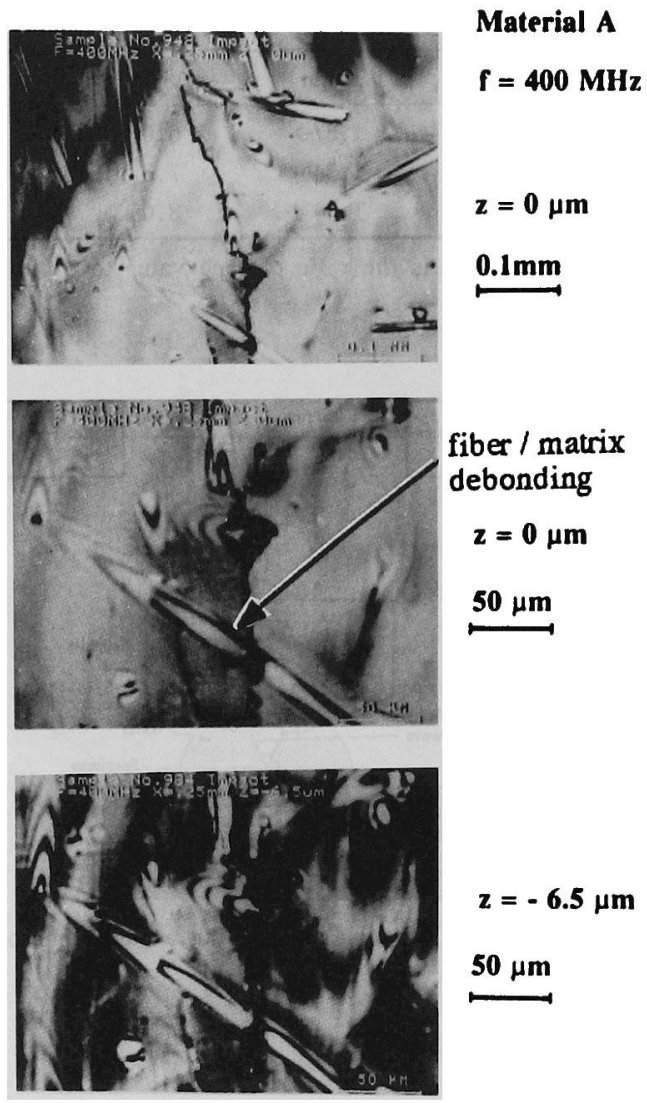

Fig. 2 SAM micrographs indicating fiber/matrix debonding (impact).

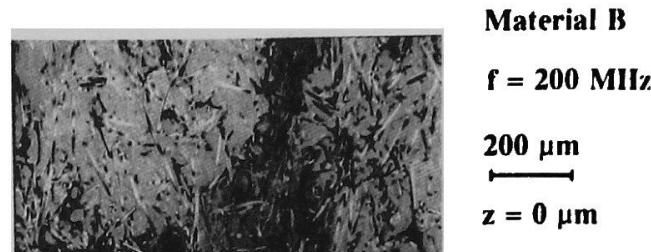

plastic

deformation

$z=-20 \mu m$

$z=-25 \mu \mathrm{m}$

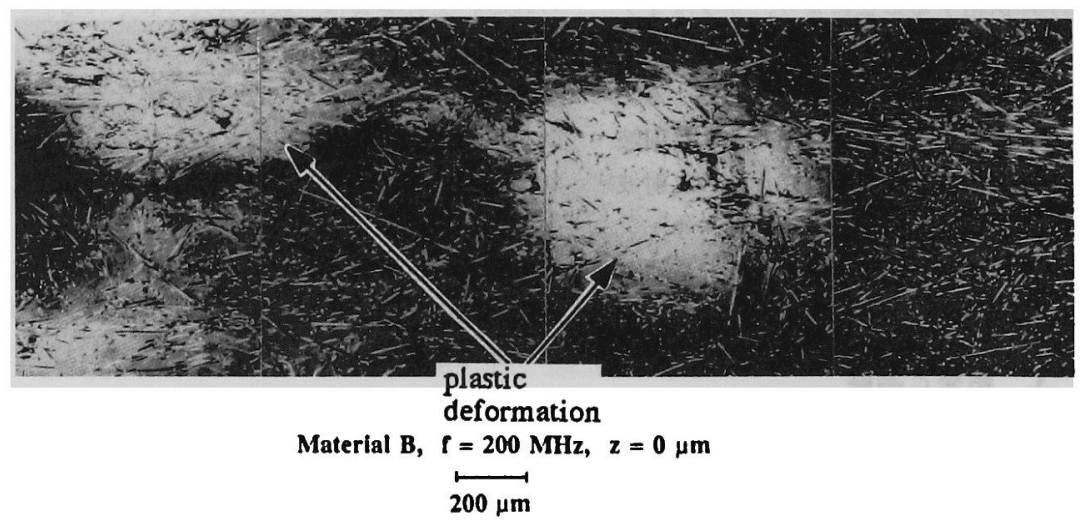

Fig. 4 SAM micrographs indicating residuel plastic defomation along crack paths.

領域は塑性変形域であり，(3)の試料中の表面波速度の差 によって生じるものと思われる。

図 4 では，表面焦点 $(z=0 \mu \mathrm{m})$ であるのもかかわらず コントラストがある。式 1 で, $Z_{1}$ =水の音響インピーダ ンス, $\mathrm{Z}_{2}=$ 樹脂相の音響インピーダンスとする。この場
合 $Z_{1}, Z_{2}$ の值は非常に近いため, 音波の反射は小さ い。亀裂両側に見られるコントラストは，主に(4)の試料 中の残留塑性変形が生じている領域と生じていない領域 における吸収の差による。この場合測定された吸収は 3 〜 $9 \mathrm{~dB}$ であった。 


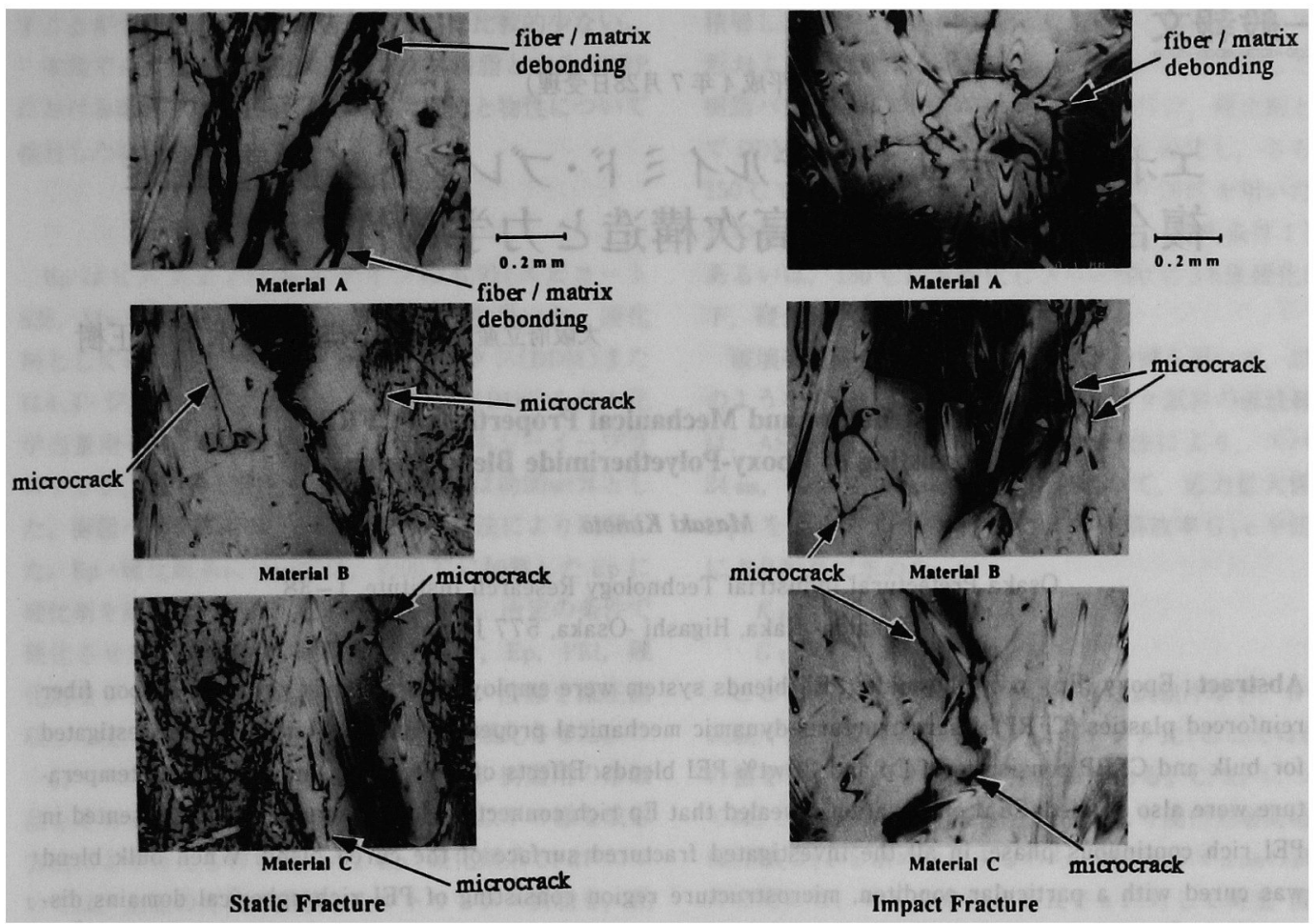

Fig. 5 Comparison of SAM micrographs for materials A. B and C (static).

試験材料による相違を図 5 (静的), 図 6 (衝撃)に示 す。材料 A では䄉維／樹脂界面強度が低いため，界面 のディボンディングが支配的で, 樹脂の塑性変形はあま り生じないままでディボンディングが次々に連結しなが ら破壊している。一方，材料 B，Cでは，亀裂先端近傍 の樹脂内にかなりの微視割れの発生が顕著である。以 上, 緎維 /樹脂界面特性の相違が, 亀裂進展挙動の相違 を引き起こすことが明らかとなった。

\section{4. 結 論}

SAM 解析によれば, 亀裂近傍の樹脂の塑性変形, 緎 維/樹脂間のディボンディングなどの微視破壊メカニズ ムが明確に観察できるのに加え，亀裂の 3 次元形状，短 䋞維配向などの情報も得られる。このことから，SAM はFRTPのマクロな静的, 衝撃力学特性を説明し得る マイクロフラクチャメカニクス解明のための実験解析法 としてきわめて有力であると言える。SAMにより得ら れた映像の波動伝播解析による理論的童づけについては 今後の研究課題としたい。また，現在引続き進めている SAM その場観察によれば，さらに定量的なマイクロフ ラクチャプロセスの理解が可能となると期待される。
Fig. 6 Comparison of SAM micrographs for material A, $B$ and $C$ (impact).

\section{謝辞}

本研究の実験に協力いただいた前 日本大学学生, 平 松哲也氏, 前 芝浦工業大学学生 古寺利男氏に感謝致 します。

\section{文献}

1. K. Friedrich, "Fracture Mechanical Behavior of Short Fiber Reinforced Thermoplastics", Fortsch. Ber., VDI-Zeitschr., Ser. 18, No. 18, 1984.

2. S. L. Kessler et al., "Instrumented Impact Testing of Plastics and Composites Materials". ASTM STP 936. ASTM, Philadelphia, 1986.

3. P. J. Hogg, Comp. Sci. Tech., 29, 89 (1987).

4. 武田展雄, 中田数夫, 強化プラスチックス, 36, 97 (1990)

5. R. A. Lemons and F. C. Quate, Appl. Phys. Rev.. 25, 251 (1974).

6. R. L. Hollis, R. Hammer, and M. Y. Al-Jaroudi, J. Mater. Sci., 19, 1897 (1984). 